\title{
A DMAIC Framework to Improve Quality and Sustainability in Additive Manufacturing-A Case Study
}

\author{
Rodrigo Rodriguez Delgadillo ${ }^{1}$, Khaled Medini ${ }^{2, *}$ (i) and Thorsten Wuest ${ }^{3}(\mathbb{C}$ \\ 1 Grenoble INP, 38031 Grenoble, France; rodrigo.rodriguez-delgadillo@grenoble-inp.org \\ 2 Mines Saint-Etienne, University Clermont Auvergne, INP Clermont Auvergne, CNRS, UMR 6158 LIMOS, \\ 42023 Saint-Etienne, France \\ 3 Industrial and Management Systems Engineering, West Virginia University, Morgantown, WV 26506, USA; \\ thwuest@mail.wvu.edu \\ * Correspondence: khaled.medini@emse.fr
}

check for updates

Citation: Rodriguez Delgadillo, R.; Medini, K.; Wuest, T. A DMAIC Framework to Improve Quality and Sustainability in Additive

Manufacturing-A Case Study. Sustainability 2022, 14, 581. https:// doi.org/10.3390/su14010581

Academic Editor: Antonella Petrillo

Received: 1 December 2021

Accepted: 1 January 2022

Published: 5 January 2022

Publisher's Note: MDPI stays neutral with regard to jurisdictional claims in published maps and institutional affiliations.

Copyright: (C) 2022 by the authors. Licensee MDPI, Basel, Switzerland. This article is an open access article distributed under the terms and conditions of the Creative Commons Attribution (CC BY) license (https:// creativecommons.org/licenses/by/ $4.0 /)$.

\begin{abstract}
Additive manufacturing as a key Industry 4.0 technology brings radical changes to how we execute production and services operations. However, this innovative technology has not reached maturity and research and development are still in progress to unleash its full sustainability potential. This paper aims to provide operational guidance to decision makers to jointly improve quality and sustainability performance of additive manufacturing processes. We propose a framework based on the DMAIC (Define/Measure/Analyze/Improve/Control) methodology and comprehensive pool of targeted key performance indicators (KPIs) and illustrate this framework through a single case study. The paper evidences the feasibility of extending DMAIC to the growing additive manufacturing domain to achieve quality and sustainability objectives. The case study uncovered some challenges, e.g., the need for customization to a company/industry context, which must be addressed in order to widely apply the proposed framework successfully.
\end{abstract}

Keywords: additive manufacturing; smart manufacturing; quality; sustainability; six sigma; agile manufacturing

\section{Introduction}

Market volatility and tough, global competition put forth various challenges ahead of companies in manufacturing and service sectors alike. At the heart of these challenges is manufacturing agility, cost-efficiency, and sustainability. In response, innovative methods and technologies are continuously developed to meet said challenges. Currently, one of the most promising technologies is Additive Manufacturing (AM), gathering significant attention from both academics and industry. This can be mainly attributed to its potential to ensure both agility and sustainability, as well as cost-efficiency in low volume production scenarios. AM is one of the key technologies of Industry 4.0 [1], and significantly influences the production environment of products/services with radical changes in the execution of operations [2].

Many companies that are using or providing this emerging technology are not only interested in obtaining economic benefits, but they want to achieve a sustained competitive advantage to stand out in the competitive market, while also addressing environmental and social challenges [3]. However, AM technology is not yet mature, and research and development is still in progress to ensure these objectives are met when implementing $\mathrm{AM}$ for various use cases. One of the major challenges related to the introduction of AM technology, is the lack of knowledge about the process and the (direct and indirect) impact on the value chain.

In order to improve the process performance and ramp-up of the production, several methodologies are presented in the literature, representing various different foci and 
areas of emphasis. Examples include but are not limited to, PDCA (Plan-Do-CheckAct), known as the Deming circle/cycle/wheel [4], and the 8D problem solving process known as a team-oriented approach to solving critical problems in manufacturing systems in a general. Another methodology within this spectrum is DMAIC (Define/Measure/Analyze/Improve/Control) [5] which offers to gain a complete and deep understanding of the process at hand based on quantitative and qualitative data. This allows decision makers to take action with proven and meaningful indicators to improve the process performance and satisfy consumer needs.

Another related area of literature related to our work focusses on analyzing the sustainability of processes and manufacturing systems. In this domain, one of the most widely used methodologies is Life Cycle Assessment (LCA) which allows evaluating the life cycle environmental impact of a product systems [6]. A set of standards have been developed to support the LCA methodology. In the same line, several recent papers extended the life cycle thinking by adding the social dimension of sustainability giving raise to concepts such as Social Life Cycle Assessment (S-LCA) [7]. Others investigated the integration of all three sustainability pillars of the Triple Bottom Line (TBL) by focusing the gaps between these concepts [8]. A common feature of these methodologies is the key role of indicators to measure and improve sustainability performance.

Recently, there was a push to unleash the potential of quality management tools and sustainability. The basic principle is to use or adapt quality and lean management tools for sustainability measurement and improvement with a major focus on the environmental pillar of sustainability [9]. This gave rise to new concepts such as Green Six Sigma [10]. The current paper is positioned in the continuum of this research line by specifically addressing the AM domain.

Research focusing on sustainability in the AM domain is emerging at a fast pace. It benefits from endeavors made in the broad manufacturing and service industries. The authors of [11] report on performance indicators for AM following the life cycle thinking and explain how to use each indicator depending on product type, application, and decision maker's goal. The literature also emphasizes the role of data-driven methods to enhance sustainability in AM [6]. From a value-driven perspective, concepts such as Circular Economy have been put forth as potential drivers of sustainability in AM [12].

The underlying research question of this study research is "how can manufacturing companies integrate quality and sustainability objectives in additive manufacturing". Following this guiding research question leads to additional objectives to make the investigation actionable and valuable to practitioners: How can we provide guidelines for manufacturing companies to address quality and sustainability performance through DMAIC methodology? In addition, to make that more specific, we will investigate this through a case study with a manufacturing company dedicated to providing 3D printing technology that has the basic know-how and associated process set-up to align with AM technological innovation.

Thus, our research methodology is comprised of a combined literature analysis and single case study to address the research question of this paper. The literature review outlines the challenges for AM and provides the conceptual foundations of the proposed framework. The case study derives insights on the applicability of the DMAIC-inspired framework based a joint work with a national company that offers innovative solutions in the field of AM in a Business-to-Business context (B2B). During the case study, three semi-structured interviews were conducted to obtain information and explore specific areas of interest.

The remainder of the paper is organized as follows: Section 2 presents the literature review, Section 3 describes the proposed framework for improving quality and sustainability, Section 4 presents a case study carried out in an AM. The importance and relevance of the study is discussed in Section 4. Sections 5 and 6 highlight some discussions and concluding remarks from the present study and some proposals for future research. 


\section{Literature Review}

\subsection{AM and Metal Binder Jetting}

AM has often been associated with 3D printing technology, which consists of building a product by deposition of material layer by layer based on a digital CAD (Computer-Aided Design) model. One of the seminal studies in this area [13] emphasizes that the advent of commercial AM systems has enabled the fabrication of parts with complex geometry directly from CAD models with minimal intervening steps. Previously, AM parts were primarily restricted to prototype demonstrator roles. Today, the viability of AM parts has evolved to the extent that they are used in production and final assemblies [13], even in the most demanding environments such as rocket nozzles and jet engines. Therefore, AM offers distinct competitive advantages such as eliminating specialized tooling costs, reducing material waste and life-cycle costs, enabling the creation of many shapes of geometries, and expanding product functionality for a variety and growing number of industrial applications.

For this study, we focus on a Binder Jetting (BJ) process relying on metal raw material as a reference. BJ is commonly used for the AM of fully functional parts with powdered materials as input. BJ is a 3D printing process that uses a liquid binding agent deposited onto a build platform to bond layers of powder material and form a part [14]. This technology can be used to print a variety of materials including metals, polymers, and ceramics. Common applications and markets for this process and its products include industrial applications of dental and medical devices, aerospace components, part casting, and luxury applications [15].

The origins of BJ technology date back to 1993, when the Massachusetts Institute Technology (MIT), developed an inkjet-based 3D printing to create three-dimensional objects using metal powders. Indeed, the term "3D printing" was originally coined by MIT in reference to the BJ technology. A manufacturing company, Extrude Hone Corporation, obtained an exclusive license for the MIT technology in 1996. Since then, the company has developed and commercialized BJ processes, with the first 3D printer, ProMetal RTS-300V delivered to Motorola in 1999 [14]. This short summary of the technology's history shows that more than 25 years have passed since this powerful and innovative way to manufacture products was introduced. Ex-one, which spun off from Extrude Hone Corporation in 2005, remained the only company to offer BJ services and systems until the early 2010s. Since then, the early patents for the technology began to expire, allowing new companies into the market. There are many companies nowadays that provide this technology.

Most of the recent studies focused on BJ technology concur on its potential benefits. Hence, it is reasonable to suggest that manufacturing companies within the target audience must explore its applications within their manufacturing processes to ensure competitive advantage against the global competition. However, modern manufacturing technologies such as BJ are inherently complex and contain many process factors with significant effects on resulting products. Further, AM, and specifically BJ, presents some specific challenges and issues that may lead to quality discrepancies [16]. Many of these challenges are caused by missing methodological approaches to control quality, and limited empirical studies and analysis of the AM systems to obtain a high level of quality of products. According to [17], the complexity of modern manufacturing technologies reinforces difficulty in operations management and quality control. Furthermore, in recent years sustainability has been become more and more important, especially in the industrial sector where the transformation of raw materials to finished products is a key. Understanding that change is inevitable, in this sense, existing quality improvement systems such as Design for Six Sigma, Six Sigma, lean principles, and other process improvement models must be adapted to integrate sustainability and complexity of modern manufacturing technologies in order to improve industrial adoption [18]. 


\subsection{Quality and Six Sigma Overview}

According to the ASCM Dictionary (Association for Supply Chain Management) quality has two major components: (i) quality of conformance, or the quality defined by the absence of defects; and (ii) quality of design, or the quality measured by the degree of customer satisfaction with a product's characteristics and features [18]. In this sense, quality can be defined as a dynamic state associated with products, services, people, processes, and environments that meets or exceeds expectations and helps produce superior value.

One of the key concepts related to quality management is Six Sigma. The Six Sigma methodology focuses on process standardization and variability reduction, in accordance with the Lean thinking approach, aiming at reducing various wastes. Six Sigma projects follow a practical roadmap called DMAIC, which is the classical cyclical process of five stages known as Define, Measure, Analyze, Improve, and Control [19]. These logical steps are used to identify and solve several kinds of problem and are reinforced through the tools offered by Industry 4.0.

The Define phase aims at identifying problems and defects within processes early on through proper data visualization tools [20]. Following the steps involved in this phase, problems can be detected including their root cause, which greatly increases the ability for analysis and optimization. In the Measure phase, data collection and analysis are the focal points. They must represent the actual situation in the field, but in many cases a lot of relevant information is lost [21,22]. In order to better exploit the collected information, it is a best practice to select and structure appropriate performance indicators. This allows conducting more target-oriented analysis where indicators are selected according to the project goals and data is collected specifically with these indicators in mind. One of the key points of Six Sigma is the versatility and the reliability of its results and in this case, the use of Key Performance Indicators (KPIs) that are well defined will help with the relevance and value of the results obtained.

In the Analyze phase, the goal is to identify and prioritize the root causes of the problem. Most of the time satisfactory analysis can be achieved with the Root Cause Analysis (also commonly known as Ishikawa or Fishbone diagram). During the Improve phase, it is essential that the action plan taken is based on the removal of real and relevant root causes and that it is monitored and sustained [20]. This analysis is crucial to fix the identified problem and/or improve the overall performance. Indicators' selection is a key for orienting and initiating improvement actions towards the achievement of the project goals. Finally, in the Control phase, the CTQs (Critical to Quality) are monitored to ensure that the performance is improving and processes are stable. This relies heavily on efficient data collection and information sharing as well as on information systems and tools such as spreadsheets or other specific software solutions. Once again, KPIs are very helpful to enable these monitoring processes and improve their efficiency.

\subsection{Six Sigma and Sustainability}

The term "sustainability" first appeared in the literature at the beginning of the 1980s. Lester R. Brown published his work "Building a Sustainable Society" in 1981 which states that in a sustainable society, harmony must exist among population growth, social welfare, financial needs, utilization of natural resources, and the minimization of pollution [23]. Sustainability means meeting our own needs without compromising the ability of future generations to meet their own needs, linking three main dimensions-economic, environmental, and social. Sustainable manufacturing is defined as the "creation of goods and services using processes and systems that are non-polluting, conserving energy and natural resources, economically viable, safe and healthful for employees, communities and consumers, and socially and creatively rewarding for all working people" [24]. This definition is aligned with the popular TBL concept promoting People, Planet, and Profit as pillars of sustainability [24]. In the last decades, concerns about sustainability have caught the attention of researchers and decision makers in industry alike. One of the most cited studies is the one by The Organization for Economic Co-operation and Development (OECD), an 
international organization that developed a Sustainable Manufacturing Toolkit providing a guideline to better manage environmental performance in manufacturing processes It "aims to provide a practical starting point for businesses around the world to improve the efficiency of their production processes and products enabling them to contribute to sustainable development and green growth" [25].

Achieving the desired quality should not overlook sustainability objectives which might even bring additional drivers of competitiveness [26]. In fact, not only Corporate Social Responsibility (CSR) brands sustainability a priority but also customer's awareness and requirements increase the pressure to include these measures in the company's targets. Therefore, considering jointly quality and sustainability in Six Sigma projects is an opportunity for achieving higher added value. This research orientation started to gain more attention during the last few years $[9,10,27-30]$.

DMAIC cycle has the potential to manage not only quality but also sustainability performance. According to [29] "DMAIC-based approach can be effectively applied to systematize the Sustainable Value Stream Mapping towards sustainable manufacturing, which includes metrics to evaluate the economic, environmental, and societal sustainability performance of a manufacturing line". In line with this definition, there are some emergent research endeavors promoting Six Sigma as powerful methodology tool to improve the sustainability performance of today's production systems [30]. A recent study stresses the importance of Green Lean Six Sigma, which is the combination of green principles with lean thinking through a Six Sigma approach [30]. The study concludes that this approach reduces negative environmental impacts and delivers high specification products.

\section{Proposed Framework}

In this section, the rationale behind the proposed framework is described, and then relevant KPIs are identified for the specific development of the framework.

\subsection{Framework Rationale}

The proposed framework is built around DMAIC to jointly improve quality and sustainability performance of AM processes. To this end, several performance indicators are identified and structured to be used mainly during the Control and Measure phases of DMAIC. The selection of the KPIs is based on a preliminary study with a company in $\mathrm{AM}$ and most importantly literature analysis. The preliminary study relied on informational interviews and some reports from the company. This led to identifying the general key aspects related to performance measurement within the company and its suppliers, customers, and partners. This helped derive a set of generic performance attributes (see Table 1, column 1). Then, for each of the performance attributes, a set of KPIs was selected from literature. This was based on a review of recent studies related to the identified, most important components of quality and sustainability found in academics papers and industry sources within the domain of AM (see Table 1, columns 2 to 4). We can see the sequence of the use of the KPIs inside the DMAIC cycle in Figure 1 presenting the proposed framework.

The KPIs identified follow some essential features namely, accuracy (reliability), relevance to decision-making (easy to understand and manage), and improvement potential (providing guidance for improving system performance). This is crucial, as most of the stakeholders involved in the DMAIC projects have to know and sympathize with the project meaning and purpose to subsequently develop and provide possible solutions. Complementarily, using these KPIs throughout the DMAIC cycle is a useful and effective way to improve a system (see Figure 1).

As a matter of fact, improving sustainability depends on a variety of interrelated factors such as democratizing the shop floor, giving frontline workforce control over their processes, empowering employees at all levels to improve processes and collaboration in decision making with better data, improving visibility, finding capacity means, objectively measuring manufacturing systems, bringing machines online, measuring human perfor- 
mance, displaying production indicators in real time and creating a shared source of truth information. Therefore, viewing operations indicators from anywhere, is likely to lead to more reliable and timely decisions related with the three components of sustainability.

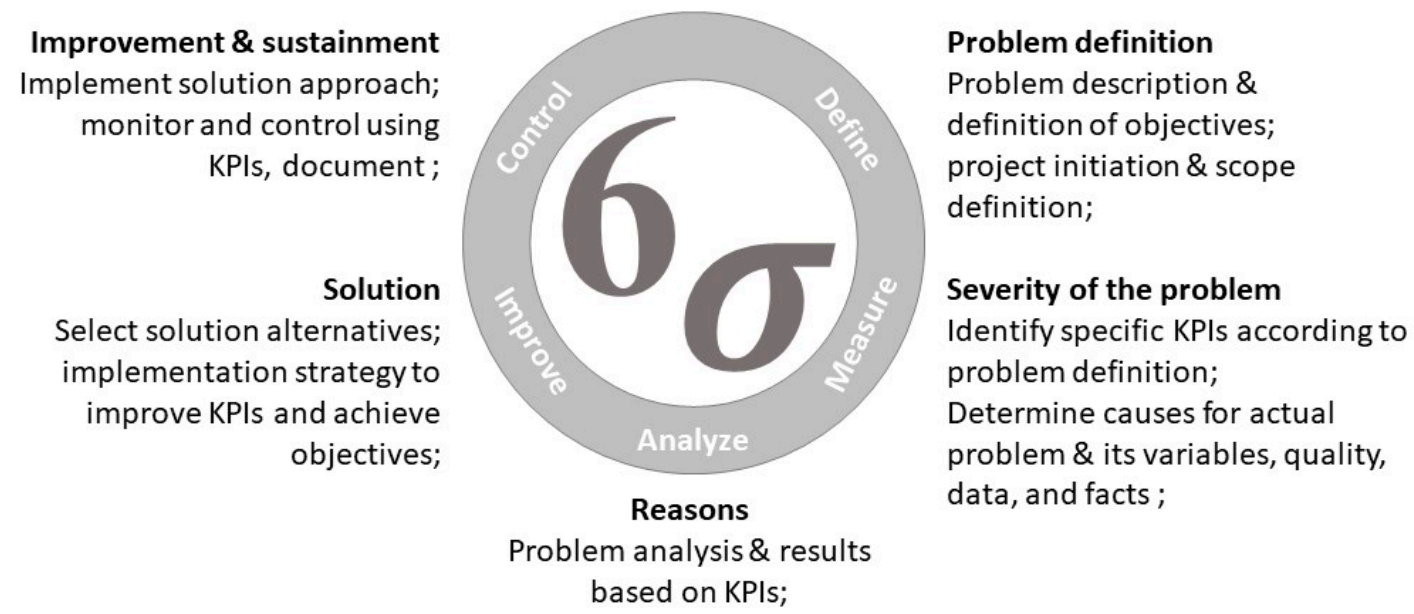

Figure 1. DMAIC cycle and KPIs.

The framework is expected to contribute directly to the TBL of sustainability. Firstly, the environmental component is addressed by monitoring $\mathrm{CO} 2$ emissions and recyclable materials that can be used to obtain better outputs. Moreover, to ensure the economic sustainability it is important to keep in mind the rational use of the financial resources to be more efficient at the time to invest. Finally, the social component is addressed from the lens of safety and (well-designed) work environment as well as health and welfare of the employees.

According to Drucker [31], "What cannot be measured cannot be controlled; what cannot be controlled cannot be managed; what cannot be managed cannot be improved". Indicators are a valuable means to measure the performance of any system and therefore they have numerous applications [14]. Indicators compress valuable information from different sources into a format that is easier to understand, compare, and manipulate. Companies can use indicators to set targets and monitor subsequent success. Interpretation becomes easier with a clear and up-to-date figure that represents the system and allows to make more wise and timely decisions. These targets help decision-makers visualize what particular actions need to be emphasized in future [24].

\subsection{Identified Performance Indicators}

The identified indicators are shown in Table 1. Indicators' identification relies predominantly on current literature in operations management and sustainability [32]. They were obtained from a deep analysis considering the most important aspects related to economic, social, and environmental issues. Since the aim is to provide a generic pool of indicators that can be adapted, the most commonly used indicators are selected from the literature. Then redundancy and duplicates are removed by the authors. This resulted in a total number of 28 unique and relevant indicators. For the complete integration of sustainability, additional indicators were added to address cost and workforce, consistently with the insights from $[33,34]$. This resulted in a list of 45 indicators. 
Table 1. KPIs List.

\begin{tabular}{|c|c|c|c|c|}
\hline Performance Attribute & KPIs & Economic & Environmental & Social \\
\hline Reliability (RL) & Order Fulfilment (OF) & $X$ & & \\
\hline Responsiveness (RS) & Order Cycle Time (OCT) & $x$ & & \\
\hline \multirow{2}{*}{ Agility (AG) } & Flexibility (FL) & $x$ & & \\
\hline & Overall Risk Value (ORV) & $x$ & & \\
\hline \multirow{3}{*}{ Internal Performance (IP) } & Production Capacity (PC) & $x$ & & \\
\hline & Productivity (PR) & $x$ & & \\
\hline & Yield (YI) & $x$ & & \\
\hline \multirow{2}{*}{ Output Performance (OP) } & Total Products Produced (TPP) & $x$ & & \\
\hline & Defect per unit (DPU) & $x$ & & \\
\hline \multirow{3}{*}{ Quality Performance (QP) } & Customer Satisfaction (CS) & $x$ & & \\
\hline & Customer Returns (CR) & $x$ & & \\
\hline & Quality Factor (QF) & $x$ & & \\
\hline \multirow{4}{*}{ Environmental Performance (EP) } & Recycled Material Fraction (RMF) & & $x$ & \\
\hline & Energy Intensity (EI) & & $x$ & \\
\hline & Greenhouse Gases (GHG) & & $x$ & \\
\hline & Solid Waste Mass (SWM) & & $X$ & \\
\hline \multirow{3}{*}{ Equipment Responsiveness (ER) } & Throughput (TH) & $x$ & & \\
\hline & Overall Equipment Effectiveness (OEE) & $x$ & & \\
\hline & Utilization (UT) & $X$ & & \\
\hline \multirow{5}{*}{ Equipment Performance (EP) } & Availability (AV) & $x$ & & \\
\hline & Performance Efficiency (PE) & $x$ & & \\
\hline & Actual Production Rate (APR) & $x$ & & \\
\hline & Failure or Breakdown Time (FBT) & $x$ & & \\
\hline & Non-Processing Time (NPT) & $x$ & & \\
\hline \multirow{4}{*}{ Inventory Turnover (INT) } & Inventory of Raw Material (IRM) & $x$ & & \\
\hline & Inventory of Material WIP (IWIP) & $x$ & & \\
\hline & Inventory of Finished Products (IFP) & $x$ & & \\
\hline & Inventory of Safety Stock (ISS) & $x$ & & \\
\hline \multirow{4}{*}{ Production Cost (PCO) } & Material Cost (MC) & $x$ & & \\
\hline & Labour Cost (LC) & $X$ & & \\
\hline & Indirect Cost (IC) & $x$ & & \\
\hline & Total Production Cost (TPC) & $x$ & & \\
\hline \multirow{4}{*}{ Quality Cost (QC) } & Prevention Cost (PC) & $x$ & & \\
\hline & Appraisal Cost (AC) & $x$ & & \\
\hline & Internal Failure Cost (IFC) & $x$ & & \\
\hline & External Failure Cost (EFC) & $X$ & & \\
\hline Asset Efficiency (ASE) & Return on Investment (RI) & $x$ & & \\
\hline \multirow{4}{*}{ HR Performance (HRP) } & Employee Turnover (ET) & & & $x$ \\
\hline & Average Experience HR (AEHR) & & & $x$ \\
\hline & Absenteeism (ABS) & & & $x$ \\
\hline & Performance Evaluation (PE) & & & $x$ \\
\hline
\end{tabular}


Table 1. Cont.

\begin{tabular}{|c|c|c|c|c|}
\hline Performance Attribute & KPIs & Economic & Environmental & Social \\
\hline \multirow{2}{*}{ HR Training } & Compliance with Training Schedule (CTS) & & & $x$ \\
\hline & Effectiveness of Trainings (ET) & & & $X$ \\
\hline \multirow{2}{*}{ Health \& Safety (H\&S) } & Labor Accidents (LAC) & & & $X$ \\
\hline & Training in Safety (TSF) & & & $X$ \\
\hline
\end{tabular}

Prior to an in-depth analysis of the manufacturing system, each indicator has to show that is provides a meaningful contribution to each stage. The selection of the KPIs for a specific application is closely related to the particular problem the company is facing [34-37]. Therefore, it is important to clearly define the real problem and the goals for a specific situation, and then select the KPIs that are useful to measure and then interpret the results. This supports a better understanding of the real and actual situations and thus determining and prioritizing possible actions to optimize the system [34].

According to Einstein "Everything should be as simple as possible, but not simpler". Therefore, it is recommended that a company first begins with simple, easy to implement measures of compliance and resource efficiency, and only then moves toward more complex indicators, such as those addressing supply chain, social effects, and life-cycle impacts. Using indicators of sustainable production is one part of the process towards continuous improvements, where the goal is to move the organization from adopting primarily lowlevel measures to using all levels of indicators of sustainable production. The criteria for the sustainability assessment of the company have to reflect several key aspects such as resources, product, environment, economic aspects, quality, and social aspects [24].

\section{Case Study}

This section applies and evaluates the proposed framework in a case study centered around an innovative company experienced in the use of AM technologies and interested in improving their quality and sustainability.

\subsection{Case Study Overview}

The aim of the case study is to illustrate the application of the DMAIC framework and the identified indicators (see Section 3) pool to improve AM performance. Therefore, we focus on a SME (Small and Medium-Sized Enterprise) given its untapped improvement potential and more agile decision making, compared to many larger manufacturing companies that are governed by a lot of standards, often already have an established set of indicators and reporting procedures. In addition, the case study aims to focus on a process which is not yet mature enough and for which ramp-up is still to be conducted to show the full potential of the proposed framework.

The involved SME is recognized as a well-known center of expertise for manufacturing, created in 1965 at the request of the manufacturing industry. The aim is to provide companies with the means and skills to increase their competitiveness, participate in standardization, create a link between scientific research and industry, promote technological advancement, help improve efficiency, and ensure quality.

The case company is developing AM processes using the BJ technology. Given the economic and environmental potential of this technology, the ambition is to rapidly and efficiently support-manufacturing companies in implementing it and ramping up their AM processes.

Therefore, it is important to address any issues from the start and standardize the processes as much as feasible in order to ease the scale-up of production. To this end, the DMAIC framework and identified KPIs pool are used to improve quality and sustainability of the AM process using BJ technology. 
BJ enables production of complex components for numerous applications. BJ is the only powered bed AM process that is not fusion-based, thus manufactured parts have no residual stresses as opposed to laser-based AM, particularly the widely used powder bed fusion processes. After the design phase of the 3D model, the manufacturing process follows six distinct phases, which are depicted here:

1. 3D Printing. The actual printing process, while fascinating to watch, should actually be the process stage that requires the least attention and interaction. Ideally, the 3D printer is able to run "lights out" without requiring constant operator monitoring or intervention.

2. Cleaning. This phase is mainly composed by two substages that are complementary: build removal that removes excess material from the build inside the printer (e.g., in powder bed processes), and removing the build from the printer and part separation that removes parts from the build plate.

3. Sintering. This phase consists of bonding the individual particles through solid-state diffusion at a temperature below the melting point of the material. However, sintering may involve liquid phase formation, also known as liquid phase sintering [14].

4. Surface Finishing. This phase utilizes machining processes to remove remaining supports, smooth surfaces, add critical features, and hit critical tolerances, polishing surfaces, coating etc.

5. Heat Treatment. This phase is set after sintering and build removal to help relieve any residual stresses that might have been introduced. Powder processes often use Hot Isostatic Pressing after part separation to decrease porosity and further relieve stresses.

6. Measurement. Also referred to as quality assurance for AM. This is not a single and one-shot activity, but instead it represents a set of inspections, measurements, analyses, and documentation performed throughout the workflow in the AM process.

\subsection{Applying the DMAIC Cycle in AM}

The Six Sigma methodology is developed through six dedicated steps (DMAIC), which seek to establish causes for the variations that occur throughout the manufacturing process. Figure 2 depicts a brief description of each step as a basis for the following application in the case study. While we introduced the basics in Section 3.2, in the following we present specific tools and methods for the proposed framework's application in the case study.

\subsubsection{Define}

For the Define phase, three key aspects are taken into account when defining the Six Sigma objectives of the particular case study. These are Voice of Customer (VOC), Critical to Quality (CTQ), and SIPOC (suppliers, inputs, process, outputs, customers) analysis. To obtain pertinent and first-hand information, a semi-structured interview was conducted with the Lead Manager of Product Development of the company. The questionnaire was designed to understand the core of the company's business and the main issues they are facing. This will enable the development of a clear picture of the potential issues the company and industry is struggling with and ultimately, support the identification of the most critical aspects to define the problems and continue with the subsequent steps.

- Voice of Customer (VOC): The main problem identified during the interview is the lack of standardized process to quality control and the big quantity of defective products obtained after all the manufacturing processes.

- $\quad$ Critical to Quality (CTQ): Problems with the recyclable raw material is an issue that is mentioned as a key point because this influences in the final product. In fact, if the proportion between virgin and recyclable material is not correct, the quality could be rejected with a considerable waste of material. Furthermore, the number of operators with special skills in critical steps inside the process is a problem that the company is currently faced by. A great part of the manufacturing process requires manual tasks where skills of operators is very important to ensure quality of the final products. In 
this sense, CTQ involves raw material recycled, skills of operators at key stages of the process.

- $\quad$ SIPOC: To have a clear vision of the SIPOC model of company, two main phases are identified: first, the design phase where the 3D model is obtained to be manufactured, second, the manufacturing phase once the design is done. The 3D printer equipment engages in the process until obtaining the final product (see Figure 2).

\section{SIPOC Analysis}

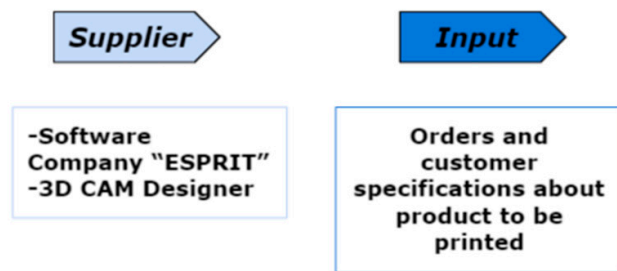

-Provider of Raw Material (Powder) "INGESSCO" and "YONTONE"

Final 3D Design

Powder:

316L,

Ti 6AiU,
Process

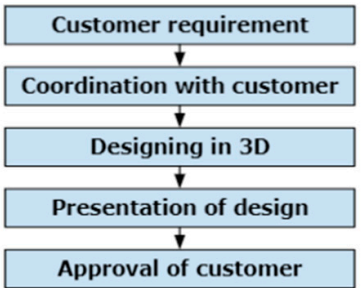

Alsilomg

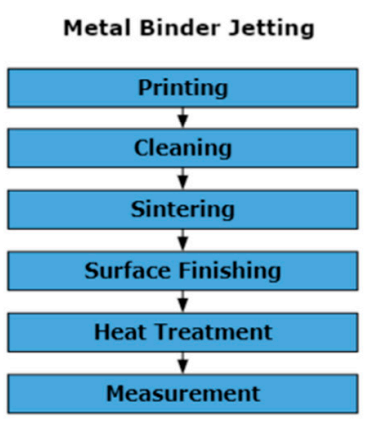

Output

Final 3D Design $\quad \begin{aligned} & \text {-Product Development } \\ & \text { Manager }\end{aligned}$

\section{(1)}

-Operations Manager

Figure 2. SIPOC Analysis of the company.

Based on the insights drawn from the interview, the case study's project goal can be defined as follows: Establish a deep analysis, considering skills in the workforce and identify actions and to minimize the quantity of defective final products within the manufacturing process using Metal Binder Jetting technology.

\subsubsection{Measure}

Once the main problems have been identified and project goal is defined, relevant KPIs are selected from the established pool (see Section 3.2) during the Measure phase. These indicators are selected and picked according to the specific problem that was identified by the case company. Table 2 presents the selected KPIs as well as their formulas, input data and calculated values. 
Table 2. Indicator's calculation.

\begin{tabular}{|c|c|c|c|}
\hline Indicator & Formula & Input Data & Value \\
\hline Defect per unit (DPU) & $\begin{array}{c}\mathrm{DPU}=\text { Defects Observed } / \# \text { units } \\
\text { processed per stage }\end{array}$ & $\begin{array}{l}14 \text { observed defects per } 100 \text { units } \\
\text { processed. }\end{array}$ & 0.14 \\
\hline $\begin{array}{l}\text { Recycled material fraction } \\
\text { (RMF) }\end{array}$ & $\begin{array}{c}\text { RMF }=\text { (Weight of recycled } \\
\text { materials consumed } / \text { Total weight } \\
\text { of all material inputs }) \times 100\end{array}$ & $\begin{array}{c}5 \mathrm{~kg} \text { of powder recycled out of } \\
\text { average of } 12 \mathrm{~kg} \text { of raw } \\
\text { material used. }\end{array}$ & $41.6 \%$ \\
\hline Availability (AV) & $\begin{array}{l}\mathrm{AV}=\text { Runtime } / \text { Planned } \\
\text { Production Time }\end{array}$ & $\begin{array}{l}1 \mathrm{~h} \text { is spent for cleaning and other } \\
\text { maintenance activities every } 10 \mathrm{~h} \\
\text { of runtime. }\end{array}$ & 0.9 \\
\hline Performance of Equipment & $\begin{array}{c}\mathrm{PE}=(\text { Parts produced } \times \text { Cycle } \\
\text { time }) / \text { Available Time } \times 100\end{array}$ & $\begin{array}{l}\text { Cycle time is } 0.1 \mathrm{~h} / \text { unit and total } \\
\text { parts produced is } 86 \text { every } 10 \mathrm{~h} .\end{array}$ & 0.955 \\
\hline Quality & $\begin{array}{c}\mathrm{Q}=\text { (\# produced parts_\# defective } \\
\text { parts }) / \# \text { produced parts }\end{array}$ & $\begin{array}{l}14 \text { observed defects per } \\
100 \text { units processed. }\end{array}$ & 0.86 \\
\hline $\begin{array}{l}\text { Overall Equipment } \\
\text { Effectiveness (OEE) }\end{array}$ & $\mathrm{OEE}=\mathrm{AV} \times \mathrm{PE} \times \mathrm{Q}$ & $\begin{array}{l}\mathrm{AV}, \mathrm{PE} \text {, and } \mathrm{Q} \text { values are } \\
\text { calculated previously }(0.9,0.955, \\
\text { and } 0.86) .\end{array}$ & $73.92 \%$ \\
\hline $\begin{array}{l}\text { Inventory of Raw Material } \\
\text { Turnover (IRMT) }\end{array}$ & $\begin{array}{l}\text { IRMT }=\text { (Amount of raw material } \\
\text { used in a month/amount of raw } \\
\text { material available in the inventory }) \\
\quad \times 100\end{array}$ & $\begin{array}{c}240 \mathrm{~kg} \text { of raw material used per } \\
\text { month and average } 300 \mathrm{~kg} \text { of } \\
\text { inventory level. }\end{array}$ & $80 \%$ \\
\hline HR Training (HRT) & $\begin{array}{c}\text { EOT }=(\text { Number of trainings } \\
\text { evaluated as positive } / \text { Total people } \\
\text { trained }) \times 100\end{array}$ & $\begin{array}{l}12 \text { training out of } 18 \text { in average } \\
\text { are evaluated as positive. }\end{array}$ & $66.67 \%$ \\
\hline
\end{tabular}

\subsubsection{Analysis}

In this phase, the system is evaluated based on the data obtained during the conducted interviews. The process was broken down into steps and diagnosed accordingly (see Figure 3). This allows to collect the necessary data to determine the quality of the product and identify the stages with the greatest probability for defective products and quality issues. This data is analyzed to determine the DPU (Defect Per Unit) and identify which stages are the most critical to act on (see Table 3).

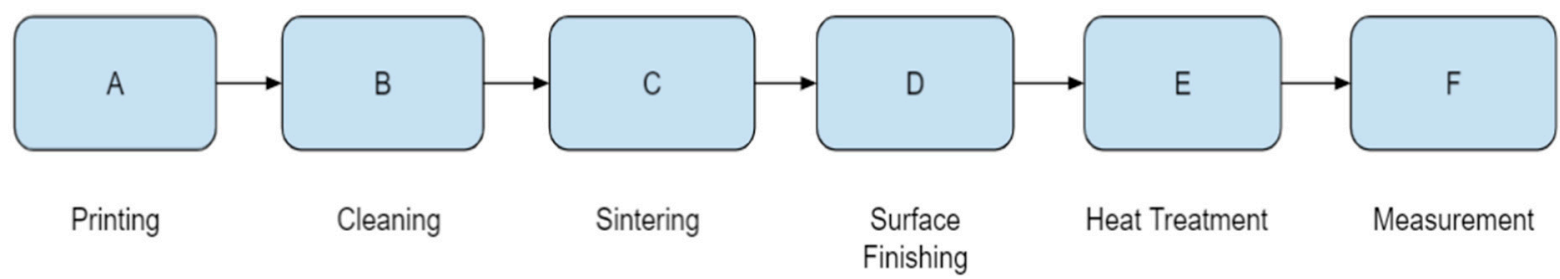

Figure 3. Stages of process.

Table 3. Percentage of contribution by stage.

\begin{tabular}{cccc}
\hline Process Stage & $\begin{array}{c}\text { DPU Contribution by Stage } \\
\text { of Process }\end{array}$ & $\begin{array}{c}\text { \% Contribution by Stage of } \\
\text { the DPU }\end{array}$ & $\begin{array}{c}\text { \% Accumulated DPU } \\
\text { E }\end{array}$ \\
\hline C & 0.26 & $30.95 \%$ & $30.10 \%$ \\
\hline B & 0.21 & $25.00 \%$ & $58.02 \%$ \\
\hline D & 0.12 & $14.29 \%$ & $72.84 \%$ \\
\hline A & 0.11 & $13.10 \%$ & $86.42 \%$ \\
\hline F & 0.08 & $9.52 \%$ & $93.83 \%$ \\
\hline
\end{tabular}


Stage analysis: The stages must be analyzed in order to determine the defects and their root causes. We can observe in Table 3 that the highest DPUs occur at stages E (Heat Treatment), C (Sintering), and B (Cleaning). Heat Treatment (E) requires a good knowledge of operators on the correct temperature and time needed to obtain a good quality in the final step. Furthermore, due to the mechanical characteristics of the equipment it is also important to manage this stage from the design phase to avoid any undesired result at this level. In the case of Sintering (C), which provides cohesion of the powders through creating strong bonds between the particles, the raw material is critical. Therefore, it is important to ensure raw material quality. Cleaning (B), which consists of removing excess material from the build inside the printer, is closely related to the effectiveness of the maintenance conducted inside the equipment which should be in optimal conditions.

Cause-Effect Analysis: For the identification of root causes of the problems at different stages, there are different quality management tools that can be employed. Within the present case study, the Cause-Effect Diagram or Ishikawa Diagram is used due to its practicality and relevance to practitioners (Figure 4).

The Cause-Effect Analysis was conducted through an additional semi-structured interview with the lead manager of product development in a brainstorming session, considering four key resources of the manufacturing system namely, methods, workforce, and materials.

The most significant root causes identified are the quality of the used raw material, reliability of the measurement of the products obtained in each stage of the process, operators' efficiency throughout the manufacturing process (especially at stages E, C, and B).

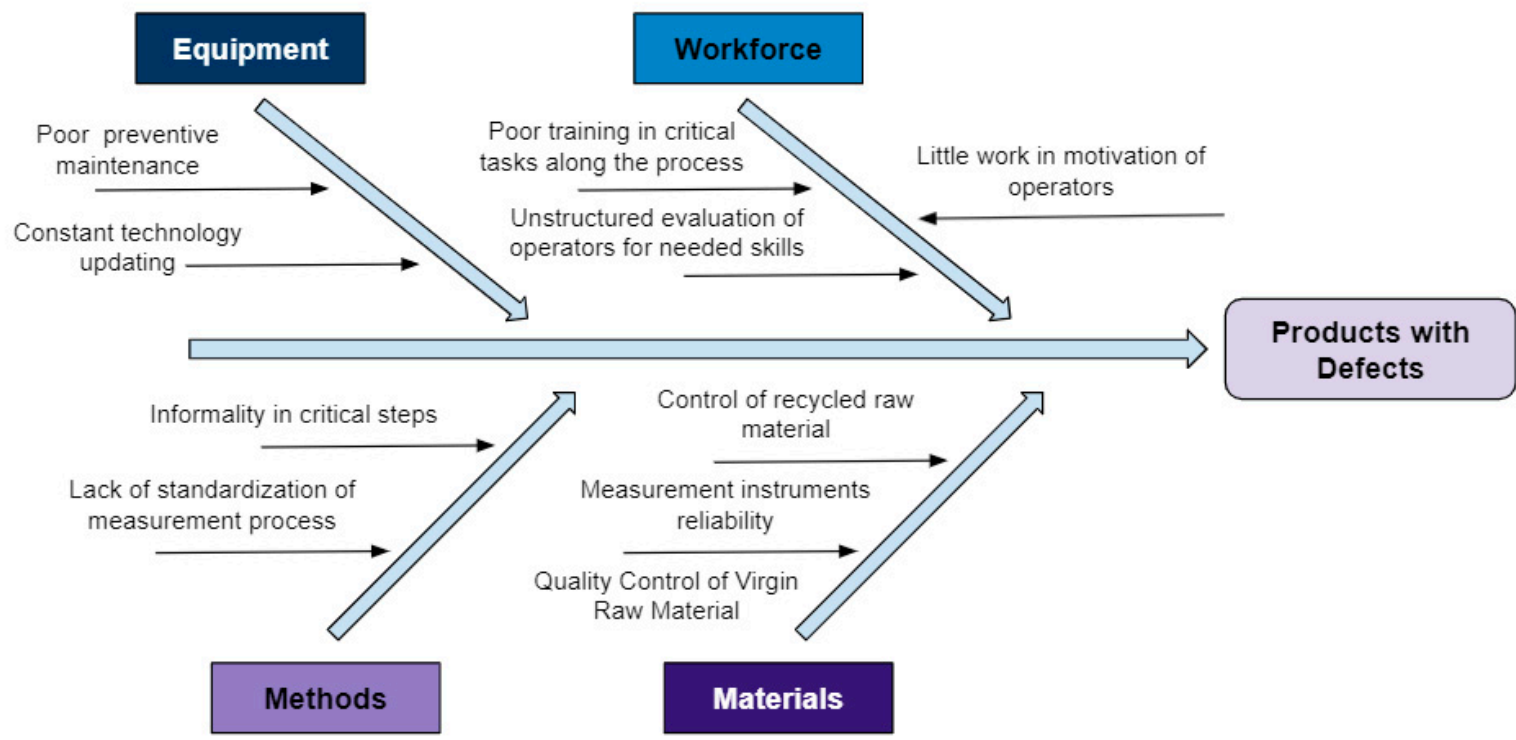

Figure 4. Cause-Effect Analysis Diagram.

\subsubsection{Improve}

According to the analysis conducted in the previous phases, the most important improvement areas are (i) input raw material quality, (ii) reliability in evaluations and measurements, and (iii) human factor efficiency.

(i) Input raw material quality. It is important to ensure the quality of the input raw materials used by the manufacturing process. This is generally true for almost all manufacturing processes; however, in AM this is even more relevant for the success of the process. In general, there are two ways of receiving the material in this specific case study: new or virgin raw material or recycled raw material.

In the case of virgin raw material, the quality control relies on inspections carried out by operators on each batch of powder received before it is introduced in the manufacturing system. These inspections should be conducted according to a quality plan and a set of 
defined specifications, complying with the standards established in AM processes. In the case of recycled raw material, a rigorous and more detailed control must be carried out on the material that is intended to be reintroduced into the manufacturing process, since it must be ensured that this material meets the necessary requirements to be able to be reused again.

(ii) Reliability in evaluations and measurements. The reliability of the evaluations carried out strongly impacts the efficiency of the whole quality management system, since the information collected from each inspection point will be used to evaluate the total quality of the final product. Therefore, quality attributes should be clearly defined and measured at different stages of the process (e.g., dimensions of the parts and surface quality). Measurement procedures should be described and made available to the operators.

(iii) Human factor efficiency. The key to improve operator's efficiency is adequate training in the activities carried out by each individual who participates directly or indirectly in this process. It is convenient to develop a training matrix per position that covers the technical and administrative needs to perform adequately given tasks. In the case of operations' personnel, developing different levels of knowledge in the product will help to give the opportunity to people who have the interest and the ability to move up in the company and seek better opportunities. The other aspect that plays an important role when it comes to the human factor is the motivation of staff at all levels. Finally, the work environment is very important for employees to perform their jobs in an efficient way. Additionally, factors such as cleanliness, safety, occupational health, lighting, and temperature play a vital role when analyzing the performance of the human factor.

\subsubsection{Control}

During the Control phase, the success of the implemented actions related to quality is evaluated. It is necessary to be clear and transparent about the way in which compliance with the expected quality standards will be evaluated. The indicators selected for the control phase are part of the proposed framework and must have a clear and objective measure, this is in order to make a comparison and measure the impact of the reduction in variability in a simple way. Table 4 summarizes the KPIs used for this purpose.

Total Customer Satisfaction. This indicator is associated with the fulfilment of quality in the provision of a service and the satisfaction perceived by the user. They are determined based on the standards defined for the provision of services. This indicator measures the degree of compliance with the standards and the level of user satisfaction.

Table 4. Total Customer Satisfaction Performance Indicators.

\begin{tabular}{cccc}
\hline KPIs & Description & Formulation & Units \\
\hline Customer satisfaction (CS) & $\begin{array}{c}\text { Measures the relationship } \\
\text { between the number of clients } \\
\text { that express to the company } \\
\text { any dissatisfaction with } \\
\text { respect to the total number of } \\
\text { clients served. }\end{array}$ & $\begin{array}{c}\text { CS }=\text { (Total client with } \\
\text { complaints and claims/Total } \\
\text { clients served) } \times 100\end{array}$ & $\%$ \\
\hline Customer Returns (CR) & $\begin{array}{c}\text { Evaluate the number of } \\
\text { returns submitted due to } \\
\text { non-conformities with the } \\
\text { product specs. }\end{array}$ & $\begin{array}{c}\text { CR }=\text { (Number of products } \\
\text { with return per batch/Total } \\
\text { number of products } \\
\text { dispatched) } \times 100\end{array}$ & $\%$ \\
\hline
\end{tabular}

Reduction in total DPU of the process. Process DPUs represent the defects that are observed during the manufacture of the product, defects created during the process in addition to those originating from the purchased parts, and that are detected before the product reaches the customers. In AM, the reduction of defects on each stage is observed through all the steps mentioned in the analysis phase. Controlling the reduction of DPU in each stage leads generally to meaningful reduction of the quantity of defective final 
products. For a given process, total DPUs represents accumulated DPUs throughout the process steps. Measures are taken every month. Furthermore, it is important to establish targets DPU values and compare each month with the real ones. An example is presented in Figure 5.

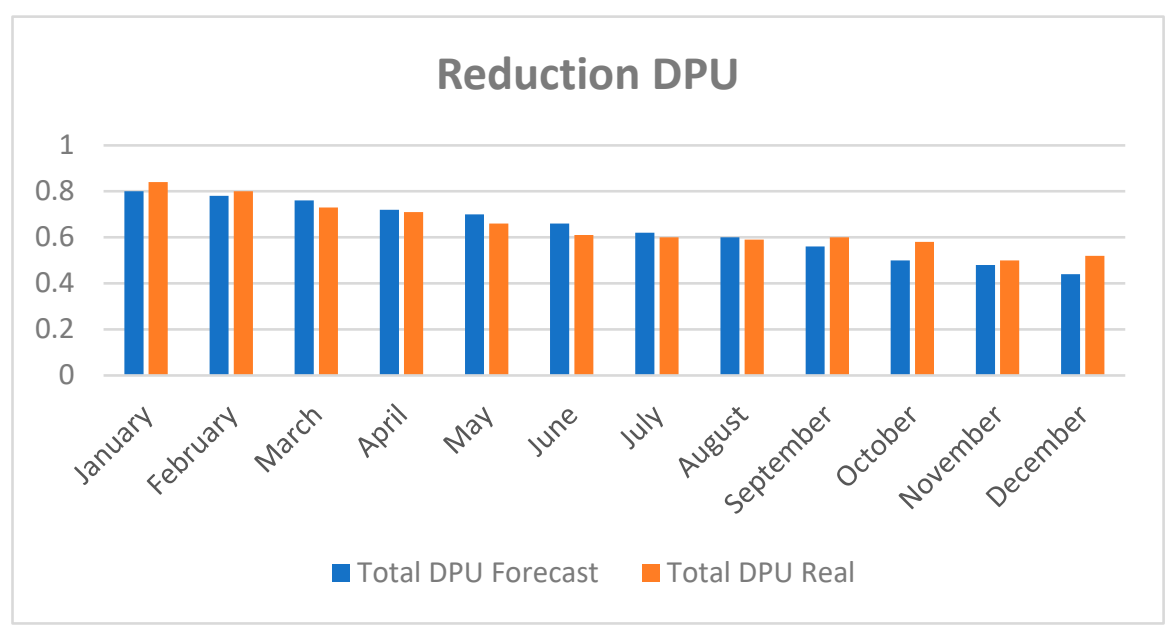

Figure 5. Reduction in total DPU of the process graph.

Productivity. With fewer defects to analyze, repair, and re-inspect, the cycle time can be reduced to almost its theoretical value. This will result in an increase in the volume of output units for a constant time. This is known as increased productivity that is, manufacturing more with the same resources or manufacturing the same with fewer resources. The following graph shows an example of a productivity index and the behavior of productivity over time. Productivity is measured in units per hour per man (Y axis) (see Figure 6).

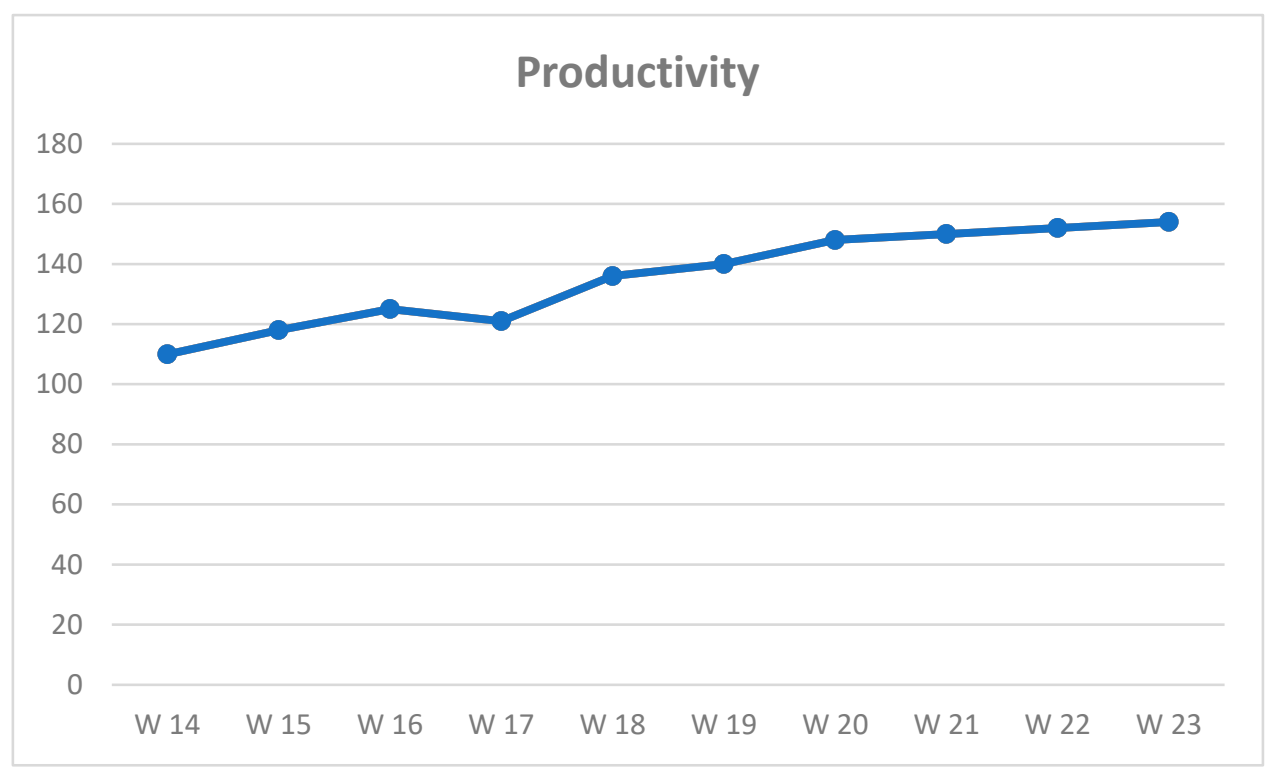

Figure 6. Productivity evolution.

\subsection{Implementation}

After applying the DMAIC framework to identify and analyze the specific problems of the case company derived actions can be completed to improve the processes. Table 5 summarizes most important proposed actions taking into account the KPIs selected from the framework. 
Table 5. Proposed actions related with indicators selected.

\begin{tabular}{ccc}
\hline Problem & (KPIs) & Proposed Action \\
\hline $\begin{array}{c}\text { Quantity of defect products obtained } \\
\text { after manufacturing process }\end{array}$ & Defect per Unit (DPU) & $\begin{array}{c}\text { Verify the proportion of raw material } \\
\text { virgin and recycled is needed to ensure } \\
\text { the reduction of defective final products. }\end{array}$ \\
$\begin{array}{c}\text { Quality of raw material that is mixed } \\
\text { with recyclable raw material as input in } \\
\text { the manufacturing system }\end{array}$ & Recycled Material Fraction (RMF) & $\begin{array}{c}\text { Implement a new step at the moment to } \\
\text { verify the quality of the recycled raw } \\
\text { material that is pretended to use again. }\end{array}$ \\
$\begin{array}{c}\text { Problems of effectiveness of the } \\
\text { equipment when is processing }\end{array}$ & Overall Equipment Effectiveness (OEE) & $\begin{array}{c}\text { Reduce the idle time of equipment and } \\
\text { use this idle time to improve steps inside } \\
\text { the production process. }\end{array}$ \\
\hline $\begin{array}{c}\text { Quantity of virgin raw material needed to } \\
\text { obtain a consistent product }\end{array}$ & Inventory of Raw Material \\
Turnover (IRMT) & $\begin{array}{c}\text { Increase the stock of virgin raw material, } \\
\text { to use more percentage at the time to } \\
\text { introduce it in the production system. }\end{array}$ \\
$\begin{array}{c}\text { Number of operators with special skills } \\
\text { in manual tasks throughout the } \\
\text { manufacturing process }\end{array}$ & Effectiveness of Trainings (EOT) & $\begin{array}{c}\text { Implement new ways to develop the } \\
\text { training, to be more personalized and } \\
\text { ensure the learning of each operator, } \\
\text { especially in critical steps. }\end{array}$ \\
\hline
\end{tabular}

\section{Discussion}

AM gained significant momentum in recent years because it offers many potential benefits. When focusing mainly on the efficiency compared to traditional manufacturing processes, AM stands out with its low tooling cost and fast ramp-up especially for smaller batch sizes that become more common with the dawn of Industry 4.0 batch-size- 1 . However, research is still needed to explore this potential in relation to other aspects such as quality and sustainability in a big picture, involving the whole value chain.

While several studies address the question of how to bridge the gap between quality and sustainability, only a few papers focus on the specific domain of AM. The proposed framework provides a means to structure the process of identifying, analyzing, and implementing pressing issues unique to a company currently utilizing or planning to utilize AM processes. The framework articulates KPIs with DMAIC to reinforce its practicality. The KPIs can cover various sustainability pillars and thus allow to holistically address sustainability and quality within operations from procurement to distribution.

The framework is kept purposely simple in a sense that it utilizes established techniques and clear guidance on how to apply it - thus ensuring broad applicability and transparency. At the same time, the proposed framework's success does rely on the willingness, motivation, and skill set at the company in question (or associated consultants).

The implementation of the proposed framework in the long run requires a multidisciplinary team, with knowledge of business managers, industrial/manufacturing engineers, and systems engineers, quality managers, etc. Improvement projects should also be supported by a suitable information system to keep all the stakeholders connected, increase data and information reliability, and optimize the process of decision-making.

Furthermore, how the proposed framework should be implemented depends in a great way on the characteristics of each company, in terms of its operations and its organizational structure. Therefore, it the presented framework is not seen as a closed recipe to follow; rather it is only a guide that should be tailored to the specific context of the companies. However, this also allows the adaptation to a variety of industries and potentially other (manufacturing) processes outside of the AM spectrum.

Knowing that one crucial aspect when a company deals with quality issues is to have real- and on-time information about the manufacturing system, Industry 4.0 exhibits a potential to support quality management systems. For instance, Industry 4.0 helps in accelerating data collection via sensor systems and IT/OT integration while reducing human error in collecting data. Furthermore, the power of advanced data analytics can 
improve the performance of Six Sigma projects. In particular, notable reduction of the time for the data collection and for conducting the relative analysis of the associated phenomenon can be achieved. In other words, these technologies allow to accelerate the so called "filters" to know in depth the process in order to highlight the root-causes which influence variations from the standard and have to be removed to optimize the process [2].

More generally, the current paper contributes to a relatively recent literature stream focusing on the synergies of agility and sustainability $[10,27,28,38,39]$. In fact, the paper shows how quality management, as a key practice in agile companies, could articulate with sustainability assessment through coupling DMAIC methodology and KPIs. This is evidenced through a single case study in AM domain. In this research orientation, sustainability requirements are not considered as a constraint but rather as an opportunity for additional value creation $[27,28,40]$. Customers play a major role at this point as a driving force for increasing companies' awareness of their CSR and ultimately improving their sustainability on the long run. In this line, strategies coupling customer centricity and sustainability improvement started to gain more attention as a means to ensure sustained competitiveness [28]. Future research in this area could benefit from recent technological development related Industry 4.0 such as big data analytics [41].

\section{Conclusions}

Sustainability is a generational challenge that encompasses the manufacturing industry. Sustainability performance of manufacturing systems had become in one of the most important tasks that most of the companies across all sectors thrive to implement. Manufacturing companies have to develop innovative solution to reduce their footprint to ensure their alignment with the needs of the future generations. Only selected studies have been developed that focus on the integration of quality and sustainability in AM to-date. The presented study contributes to bridging this gap by combining a preselected set of KPIs/indicators with DMAIC and evaluating the implementation in an industrial case study.

First, after a deep analysis of the most pertinent indicators, this study proposed a set of KPIs in a structured way, stressing that two areas are responsible to lead this phase: Operations and Human Resources Management. Therefore, a well-structured training planning will help to achieve better results in the outputs of the manufacturing system. This study highlights a step-by-step guide to conduct this process and achieve the objective.

Second, this study presents via single case study the practical implementation of the proposed framework by coupling Six Sigma and KPIs that have some mandatory features such as reliability, meaningful to decision making, and easy to understand. The framework could be very useful to improve quality and sustainability by following the DMAIC cycle and using pre-selected KPIs.

Finally, the present study provides a step forward towards the integration of quality and sustainability considerations in AM. This is likely to support production rampup due to standardization and improved performance of the processes, taking into account the improvement of the manufacturing systems identifying key areas inside the organizational structure.

However, the work also has some limitations that the reader needs to carefully consider when interpreting the presented results. First and foremost, the case study is based on a single case study, therefore, the generalizability beyond the case company and the focal process (Metal Binder Jetting) cannot be guaranteed. Furthermore, the KPIs and input feeding in the analysis is heavily dependent on the qualitative data obtained from the company's stakeholders at this point. In future work, the application of more quantitative measures and inclusion of sensor data in the analysis phase is an interesting option.

Author Contributions: Conceptualization, R.R.D. and K.M.; methodology, R.R.D., K.M. and T.W.; validation, R.R.D., K.M. and T.W.; formal analysis, R.R.D., K.M. and T.W.; investigation, R.R.D., K.M. and T.W.; writing—original draft preparation, R.R.D., K.M.; writing—review and editing, R.R.D., 
K.M. and T.W.; supervision, K.M.; project administration, K.M. and T.W.; funding acquisition, K.M. and T.W. All authors have read and agreed to the published version of the manuscript.

Funding: This work is partly supported by Face Foundation through SUSTAIN project (https: / / sustainproject.wp.imt.fr/, accessed on 25 November 2021), and by Auvergne Rhône Alpes (AURA) Region through VARIETY project (https:/ / variety.wp.imt.fr/, accessed on 25 November 2021).

Informed Consent Statement: Not applicable.

Conflicts of Interest: The authors declare no conflict of interest.

\section{References}

1. Mittal, S.; Kahn, M.; Romero, D.; Wuest, T. Smart Manufacturing: Characteristics, Technologies and Enabling Factors. Part B J. Eng. Manuf. 2019, 233, 1342-1361. [CrossRef]

2. Dombrowski, U.; Wullbrandt, J.; Krenkel, P. Industrie 4.0 in production ramp-up management. In Proceedings of the 28th International Conference on Flexible Automation and Intelligent Manufacturing, Columbus, OH, USA, 11-14 June 2018; Volume 17, pp. 1015-1022.

3. Abdalla, H.; Fattah, K.P.; Abdallah, M.; Tamimi, A.K. Environmental Footprint and Economics of a Full-Scale 3D-Printed House. Sustainability 2021, 13, 11978. [CrossRef]

4. Milgram, L.; Spector, A.; Treger, M. Plan, Do, Check, Act: The Deming or Shewhart Cycle. In Managing Smart; Milgram, L., Spector, A., Treger, M., Eds.; Gulf Professional Publishing: Woburn, MA, USA, 1999.

5. De Mast, J.; Lokkerbol, J. An analysis of the Six Sigma DMAIC method from the perspective of problem solving. Int. J. Prod. Econ. 2012, 139, 604-614. [CrossRef]

6. Li, T.; Yeo, J. Strengthening the Sustainability of Additive Manufacturing through Data-Driven Approaches and Workforce Development. Adv. Intell. Syst. 2021, 3, 12. [CrossRef]

7. Huarachi, D.A.R.; Piekarski, C.M.; Puglieri, F.N.; de Francisco, A.C. Past and future of Social Life Cycle Assessment: Historical evolution and research trends. J. Clean. Prod. 2020, 264, 121506. [CrossRef]

8. Hoogmartens, R.; Van Passel, S.; Van Acker, K.; Dubois, M. Bridging the gap between LCA, LCC and CBA as sustainability assessment tools. Environ. Impact Assess. Rev. 2014, 48, 27-33. [CrossRef]

9. Garza-Reyes, J.A.; Romero, J.T.; Govindan, K.; Cherrafi, A.; Ramanathan, U. A PDCA-based approach to Environmental Value Stream Mapping (E-VSM). J. Clean. Prod. 2018, 180, 335-348. [CrossRef]

10. Sagnak, M.; Kazancoglu, Y. Integration of green lean approach with six sigma: An application for flue gas emissions. J. Clean. Prod. 2016, 127, 112-118. [CrossRef]

11. Taddese, G.; Durieux, S.; Duc, E. Sustainability performance indicators for additive manufacturing: A literature review based on product life cycle studies. Int. J. Adv. Manuf. Technol. 2020, 107, 3109-3134. [CrossRef]

12. Colorado, H.; Gutierrez, E.; Neves, S. Sustainability of additive manufacturing: The circular economy of materials and environmental perspectives. J. Mater. Res. Technol. 2020, 9, 8221-8234. [CrossRef]

13. Yang, H.; Rao, R.; Simpson, T.; Lu, Y.; Witherell, P.; Nassar, A.; Reutzel, E.; Kumara, S. Six-sigma quality management of additive manufacturing. Proc. IEEE Conf. 2020, 109, 347-376. [CrossRef] [PubMed]

14. Erazo, A.L.; Apaltegui, N.A.; Agote, I.; Zuza, E. A review on recent developments in binder jetting metal additive manufacturing: Materials and process characteristics. Powder Metall. 2019, 62, 24-28.

15. Ziaee, M.; Crane, N.B. Binder jetting: A review of process, materials, and methods. Addit. Manuf. 2019, 28, 781-801. [CrossRef]

16. Li, M.; Du, W.; Elwany, A. Metal Binder Jetting Additive Manufacturing: A Literature Review. Manuf. Sci. Eng. 2020, 142, 35-42. [CrossRef]

17. Elmaraghy, W.; Elmaraghy, H.; Tomiyama, T. Complexity in engineering design and manufacturing. Manufaturing Technol. 2012, 61, 793-814. [CrossRef]

18. Blackstone, H.; Jonah, J. APICS Dictionary, 13th ed.; The Association for Operations Management: Chicago, IL, USA, 2010; pp. 45-46.

19. Kaswan, M.S.; Rathi, R. Green Lean Six Sigma for sustainable development: Integration and framework. Environ. Impact Assess. Rev. 2020, 83, 106396. [CrossRef]

20. Antony, J.; Vijaya, S.; Chad, L.; Elizabeth, C. Lean Six Sigma Sustainability. In The Ten Commandments of Lean Six Sigma; Emerald Publishing Limited: Bingley, UK, 2019; pp. 83-89.

21. Erdil, N.O.; Arani, O.M. Embedding sustainability in lean six sigma efforts. J. Clean. Prod. 2018, 198, 520-529. [CrossRef]

22. Albliwi, S.; Antony, J. A systematic review of Lean Six Sigma for the manufacturing industry. Comput. Sci. 2015, 21, 79-84. [CrossRef]

23. Brown, L.R. Building a Sustainable Society; United Nations Fund for Population Activities: New York, NY, USA, 1981 ; pp. 15-16.

24. Krajns, D.; Glavic, P. Indicators of Sustainable Production. Clean Technol. Environ. Policy 2003, 9, 519-549.

25. Organization for Economic Cooperation and Development (OECD). OECD Sustainable Manufacturing Toolkit; Directorate for Science and Technology and Industry (DCTI): Paris, France, 2011; pp. 17-26. 
26. Rousseau, M.; Medini, K.; Romero, D.; Wuest, T. Configurators as a mean to Leverage Customer-Centric Sustainable SystemsEvidence from the 3D-Printing Domain. In Proceedings of the 8th CIRP Global Web Conference-Flexible Mass Customization, Leuven, Belgium, 14-16 October 2020; Volume 96, pp. 103-108.

27. Medini, K.; Wuest, T.; Romero, D.; Laforest, V. Integrating Sustainability Considerations into Product Variety and Portfolio Management. In Proceedings of the 53rd CIRP Conference on Manufacturing Systems, Chicago, IL, USA, 1-3 July 2020; Volume 93, pp. 605-609.

28. Pardo-Jaramillo, S.; Muñoz-Villamizar, A.; Osuna, I.; Roncancio, R. Mapping research on customer centricity and sustainable organizations. Sustainability 2020, 12, 7908. [CrossRef]

29. Jarnil, N.; Gholami, H.; Mat Saman, M.Z.; Streimikiene, D.; Sharif, S. DMAIC-based approach to sustainable value stream mapping: Towards a sustainable manufacturing system. Econ. Res.-Ekon. 2020, 33, 331-360.

30. Farrukh, A.; Mathrani, S.; Taskin, N. Investigating the Theoretical Constructs of a Green Lean Six Sigma Approach towards Environmental Sustainability: A Systematic Literature Review and Future Directions. Sustainability 2020, 12, 8247. [CrossRef]

31. Drucker, P.; Maciariello, J. Management; Harper Collins, The Drucker Institute: Claremont, CA, USA, 1999; Volume 91711, pp. 345-352.

32. Azapagic, A.; Perdan, S. Indicators of Sustainable Development for Industry. Process Saf. Environ. Prot. 2000, 78, $243-261$. [CrossRef]

33. Carlson, K.; Kavanagh, M. HR metrics and Workforce analysis. In Human Resources Information Systems: Basics, Applications, and Future Directions; Sage Publications Inc.: Newbury Park, CA, USA, 2008; pp. 166-198.

34. Leffakis, Z.M. A Framework to Identify Best Quality Management Practices and Techniques for Diverse Production Ramp-up Environments: Propositions for Future Research. Qual. Manag. J. 2017, 23, 20-44. [CrossRef]

35. Medini, K.; Da Cunha, C.; Bernard, A. Tailoring performance evaluation to specific industrial contexts-Application to sustainable mass customization enterprises. Int. J. Prod. Res. 2015, 53, 2439-2456. [CrossRef]

36. Peng, T.; Chen, C.; Kellens, K. Sustainability of Additive Manufacturing: An overview on its energy demand and environmental impact. Addit. Manuf. 2018, 21, 694-704. [CrossRef]

37. Hristov, I.; Chirico, A. The Role of Sustainability Key Performance Indicators (KPIs) in Implementing Sustainable Strategies. Sustainability 2019, 11, 5742. [CrossRef]

38. Geyi, D.G.; Yusuf, Y.; Menhat, M.S.; Abubakar, T.; Ogbuke, N.J. Agile capabilities as necessary conditions for maximising sustainable supply chain performance: An empirical investigation. Int. J. Prod. Econ. 2020, 222, 107501. [CrossRef]

39. Chambers, J.M.; Wyborn, C.; Klenk, N.L.; Ryan, M.; Serban, A.; Bennett, N.J.; Brennan, R.; Charli-Joseph, L.; Fernández-Giménez, M.E.; Galvin, K.A.; et al. Co-productive agility and four collaborative pathways to sustainability transformations. Glob. Environ. Chang. 2022, 72, 102422. [CrossRef]

40. SUSTAIN. Steering Variety and Complexity in Operations Management towards Sustainability. 2021. Available online: https: / / sustainproject.wp.imt.fr/ (accessed on 29 November 2021).

41. Raut, R.D.; Mangla, S.K.; Narwane, V.S.; Dora, M.; Liu, M. Big Data Analytics as a mediator in Lean, Agile, Resilient, and Green (LARG) practices effects on sustainable supply chains. Transp. Res. Part E Logist. Transp. Rev. 2021, 145, 102170. [CrossRef] 